\title{
HUBUNGAN STATUS EKONOMI DENGAN PERILAKU HIDUP BERSIH DAN SEHAT DALAM RUMAH TANGGA
}

\author{
Faisal Ibnu, Emyk Windartik, Indra Yulianti \\ STIKES Bina Sehat PPNI Mojokerto \\ Email: masfaizppni@gmail.com
}

\begin{abstract}
ABSTRAK
Perilaku Hidup Bersih dan Sehat (PHBS) merupakan pengalaman belajar atau menciptakan suatu kondisi bagi perorangan, keluarga, kelompok dan masyarakat dengan cara membuka jalur komunikasi, memberikan informasi dan melakukan edukasi, untuk meningkatkan pengetahuan, sikap dan perilaku, melalui pendekatan pimpinan, bina suasana dan pemberdayaan masyarakat. Status ekonomi sangat erat berkaitan dengan penerapan PHBS. Penelitian ini bertujuan untuk mengetahui hubungan status ekonomi dengan perilaku hidup bersih dan sehat (PHBS) dalam rumah tangga di Dusun Muteran Desa Wonodadi Kecamatan Kutorejo Kabupaten Mojokerto. Desain penelitian dalam penelitian ini adalah analitik dengan pendekatan cross sectional. Populasi pada penelitian ini adalah semua kepala keluarga di Dusun Muteran Desa Wonodadi Kecamatan Kutorejo Kabupaten Mojokerto sebanyak 112 orang menggunakan teknik sistematik random sampling hingga didapatkan sampel 88 orang. Instrumen yang digunakan untuk mengumpulkan data dengan menggunakan lembar observasi dengan cara menggunakan editing, coding, scoring, tabulating dan rank spearman. Hasil uji Rank Spearman menunjukkan nilai $\rho$ sebesar 0,000 , dimana $\rho=0,000<0,05$ maka artinya terdapat hubungan antara status ekonomi dengan perilaku hidup bersih dan sehat di Dusun Muteran Desa Wonodadi Kecamatan Kutorejo Kabupaten Mojokerto. Hal ini menunjukkan bahwa semakin tinggi status sosial ekonomi maka semakin baik pula perilaku hidup bersih dan sehat. Hasil ini menunjukkan bahwa status ekonomi sangat erat berkaitan dengan perilaku hidup bersih dan sehat.
\end{abstract}

Kata Kunci : Perilaku Hidup Bersih dan Sehat, Status Ekonomi

\section{ABSTRACT}

Living clean and healthy behaviors (PHBS) is a learning experience or creating a condition for individuals, families, groups and communities by opening with communication, provide information and conduct education, to increase knowledge, attitude and behavior, leadership, community development approach through the atmosphere and community empowerment. Economic status is very closely related to the application of the PHBS. This research aims to know the relationship of economic status with a clean and healthy living behaviours (PHBS) in household in Wonodadi Village Muteran Village sub district Kutorejo Mojokerto. The design of the research in this study was analytic with cross sectional approach. The population in this research is all the heads of families in the hamlet of Muteran village of Kutorejo Sub-district Wonodadi Mojokerto as many as 112 people. The samples on this research totalled 88 families were taken using systematic random sampling techniques. Instruments used to collect data 
using observation sheet and data analysis using the spearman rank test. Spearman Rank test results show the value of $\rho$, where $\rho=0.000<$ the 0.05 . It's means that there is a relationship between economic status with clean and healthy lifestyles in the hamlet of Muteran village of Kutorejo Sub-district Wonodadi Mojokerto. This suggests that the higher socio-economic status then the better lifestyles also clean and healthy. These results indicate that economic status is very closely related to the behavior of living clean and healthy..

\section{Keywords: Clean and Healthy Living Behavior, Economic Status}

\section{PENDAHULUAN}

Perilaku Hidup Bersih dan
Sehat (PHBS) memberikan
pengalaman belajar atau
menciptakan suatu kondisi bagi perorangan, keluarga, kelompok dan masyarakat dengan membuka jalur komunikasi, memberikan informasi dan melakukan edukasi, untuk meningkatkan pengetahuan, sikap dan perilaku, melalui pendekatan pimpinan (Advocacy), bina suasana (social support) dan pemberdayaan masyarakat (Empowerment) (Dinkes, 2008). PHBS di Rumah Tangga adalah upaya untuk memberdayakan anggota rumah tangga agar tahu, mau dan mampu melaksanakan perilaku hidup bersih dan sehat serta berperan aktif dalam gerakan kesehatan di masyarakat.

Menurut Laporan

Akuntanbilitas Kinerja Kementrian Kesehatan RI tahun 2014 bahwa target rumah tangga ber-PBHS adalah $70 \%$. Dari yang ditargetkan pemerintah sebesar $70 \%$ tersebut propinsi Jawa Timur capaiannya masih dibawah standar yaitu 48,3\%. Berdasarkan data Riskesdas 2007 \& Riskesdas 2013, ada sejumlah faktor risiko perilaku kesehatan yang terjadi, yakni penduduk kurang aktivitas fisik $(26,1 \%)$, perilaku merokok penduduk sejak usia dini $(36,3 \%)$, penduduk $>10$ tahun kurang konsumsi buah dan sayur $(93,5 \%)$, penduduk $>10$ th minum minuman beralkohol $(4,6 \%)$.

Hasil penelitian Zaahara yang dilakukan di Bekasi (2001), status sosial ekonomi yang meliputi (1) jenis pekerjaan, (2) pendidikan, (3) pemilikan aset dan (4) prestis berupa penghormatan masyarakat dilihat dari kedudukan formal, informal maupun lembaga adat dan agama mempunyai hubungan positif dan signifikan dengan perilaku hidup sehat dalam keluarga (Furwanto, 2013). Hasil studi pendahuluan Dusun Muteran Desa Wonodadi Kecamatan Kutorejo Kabupaten Mojokerto pada 15 November 2017 dengan cara melakukan wawancara dengan 10 orang didapatkan $30 \%$ atau 3 orang mengatakan bahwa mereka sudah melaksanakan 10 indikator PHBS dalam tatanan rumah tangga dan $70 \%$ atau 7 orang mengatakan bahwa belum melaksanakan 10 indikator PHBS dalam tatanan rumah tangga, antara lain anggota keluarga masih merokok, kurangnya pemberian ASI Ekslusif, dan lantai rumah masih terbuat dari tanah.

Untuk mewujudkan sebuah bangsa yang lebih sehat, masyarakat diajak berkomitmen untuk melakukan hidup sehat melalui perilaku hidup bersih dan sehat. Terpenuhinya indikator phbs dalam tatanan rumah tangga menjadikan keluarga tersebut termasuk dalam 
phbs sehat. Sedangkan yang tidak memenuhi indikator phbs dikatakan phbs tidak sehat. Agar terpenuhinya phbs dalam tatanan rumah tangga yang sehat, maka sangat penting adanya promosi kesehatan. Menurut pusat promosi kesehatan, PHBS dapat dapat mencegah terjadinya penyakit dan melindungi diri dari ancaman penyakit. Dampak Perilaku Hidup Bersih dan Sehat (PHBS) yang tidak baik dapat menimbulkan suatu penyakit diantaranya adalah mencret, muntaber, desentri, typus, dan DBD.

\section{METODE PENELITIAN}

Rancangan penelitian ini adalah analitik korelasi metode rancangan cross sectional. Populasinya adalah semua anggota keluarga di Dusun Muteran Desa Wonodadi Kecamatan Kutorejo Kabupaten Mojokerto sebanyak 112 orang. Pengambilan sampel menggunakan teknik Probability sampling dengan jenis Sistematis Random Sampling (pengambilan sampel acak sistematik). Sampel yang diambil berjumlah 88 responden. Penelitian dilakukan pada tanggal 12 - 25 Maret 2018. Pada penelitian ini variabel independen status ekonomi dan variabel dependen perilaku hidup bersih dan sehat. Alat ukur menggunakan lembar observasi. Analisa data menggunakan uji Rank Spearman.

\section{HASIL}

Tabel 1: Distribusi Frekuensi Responden Berdasarkan Pendidikan Di Dusun Muteran Desa Wonodadi Kecamatan Kutorejo

Kabupaten Mojokerto Maret 2018

\begin{tabular}{cccc}
\hline No & Pendidikan & $\begin{array}{c}\text { Frekuensi } \\
\text { (f) }\end{array}$ & Presentase (\%) \\
\hline 1 & Tidak Sekolah & 4 & 4.5 \\
2 & SD & 36 & 40.9 \\
3 & SMP & 22 & 25.0 \\
4 & SMA & 18 & 20.5 \\
5 & Perguruan & 8 & 9.1 \\
& Tinggi & & 100.0 \\
\hline
\end{tabular}

Berdasarkan tabel 1 diketahui bahwa hampir setengah dari responden berpendidikan SD yaitu sebanyak 36 orang (40.9\%).

Tabel 2: Distribusi Frekuensi Responden Berdasarkan Umur Di Dusun Muteran Desa Wonodadi Kecamatan Kutorejo Kabupaten Mojokerto Maret 2018.

\begin{tabular}{cccc}
\hline No & Umur & Frekuensi (F) & Presentase (\%) \\
\hline 1 & $17-25$ tahun & 0 & 0 \\
2 & $26-35$ tahun & 4 & 4.5 \\
3 & $36-45$ tahun & 13 & 14.8 \\
4 & $46-55$ tahun & 71 & 80.7 \\
\hline & Total & 88 & 100.0 \\
\hline
\end{tabular}


Berdasarkan tabel 2 diketahui bahwa sebagian besar responden berumur 46-55 tahun yaitu sebanyak 71 orang $(80.7 \%)$.

Tabel 3: Distribusi Frekuensi Responden Berdasarkan Pekerjaan Ayah Di Dusun Muteran Desa Wonodadi Kecamatan Kutorejo Kabupaten Mojokerto Maret 2018.

\begin{tabular}{clcc}
\hline No & Pekerjaan Ayah & Frekuensi (F) & Presentase (\%) \\
\hline 1 & PNS / ABRI & 11 & 12.5 \\
2 & Swasta & 38 & 43.2 \\
3 & Buruh & 27 & 30.7 \\
4 & Tidak Bekerja & 12 & 13.6 \\
\hline \multicolumn{2}{r}{ Total } & 88 & 100.0 \\
\hline
\end{tabular}

Berdasarkan tabel 3 diketahui bahwa hampir setengah dari responden bekerja sebagai Swasta yaitu sebanyak 38 orang (43.2\%).

Tabel 4: Distribusi Frekuensi Responden Berdasarkan Jumlah Anggota Keluarga Di Dusun Muteran Desa Wonodadi Kecamatan Kutorejo Kabupaten Mojokerto Maret 2018.

\begin{tabular}{llcc}
\hline No & $\begin{array}{c}\text { Jumlah Anggota } \\
\text { Keluarga }\end{array}$ & Frekuensi (F) & Presentase (\%) \\
\hline 1 & $2-5$ & 40 & 45.5 \\
2 & $6-10$ & 47 & 53.4 \\
3 & $>10$ & 1 & 1.1 \\
\hline \multicolumn{2}{r}{ Total } & 88 & 100.0 \\
\hline
\end{tabular}

Berdasarkan tabel 4 diketahui bahwa sebagian dari responden jumlah anggota keluarga dalam rumah terdapat 6-10 sebanyak 47 orang (53.4\%).

Tabel 5: Distribusi Frekuensi Status Ekonomi Di Dusun Muteran Desa Wonodadi Kecamatan Kutorejo Kabupaten Mojokerto Maret 2018.

\begin{tabular}{llcc}
\hline No & \multicolumn{1}{c}{ Status Ekonomi } & Frekuensi (F) & Presentase (\%) \\
\hline 1 & Keluarga Pra Sejahtera & 22 & 25.0 \\
2 & Keluarga Sejahtera I & 32 & 36.4 \\
3 & Keluarga Sejahtera II & 17 & 19.3 \\
4 & Keluarga Sejahtera III & 13 & 14.8 \\
5 & Keluarga Sejahtera III & 4 & 4.5 \\
& Plus & & \\
\hline \multicolumn{2}{c}{ Total } & 88 & 100.0 \\
\hline
\end{tabular}

Berdasarkan tabel 5 diketahui bahwa sebagian status ekonomi responden termasuk Keluarga Sejahtera I yaitu sebanyak 32 orang (36.4\%). 
Tabel 6: Distribusi Frekuensi Perilaku Hidup Bersih dan Sehat Di Dusun Muteran Desa Wonodadi Kecamatan Kutorejo Kabupaten Mojokerto Maret 2018.

\begin{tabular}{llcc}
\hline No & $\begin{array}{c}\text { Perilaku Hidup Bersih } \\
\text { dan Sehat }\end{array}$ & Frekuensi (F) & Presentase (\%) \\
\hline 1 & Merah & 5 & 5.7 \\
2 & Kuning & 40 & 45.5 \\
3 & Hijau & 31 & 35.2 \\
4 & Biru & 12 & 13.6 \\
\hline \multicolumn{2}{r}{ Total } & 88 & 100.0 \\
\hline
\end{tabular}

Berdasarkan tabel 6 diketahui bahwa sebagian perilaku hidup bersih dan sehat yang dimiliki responden adalah Kuning yaitu sebanyak 40 orang (45.5\%).

Tabel 7: Tabulasi Silang Hubungan Status Ekonomi Dengan Perilaku Hidup Bersih Dan Sehat Di Dusun Muteran Desa Wonodadi Kecamatan Kutorejo Kabupaten Mojokerto Maret 2018.

\begin{tabular}{|c|c|c|c|c|c|c|c|c|c|c|}
\hline \multirow{3}{*}{$\begin{array}{c}\text { Status } \\
\text { Ekonomi }\end{array}$} & \multicolumn{8}{|c|}{ PHBS } & \multirow{2}{*}{\multicolumn{2}{|c|}{ Total }} \\
\hline & \multicolumn{2}{|c|}{ Merah } & \multicolumn{2}{|c|}{ Kuning } & \multicolumn{2}{|c|}{ Hijau } & \multicolumn{2}{|c|}{ Biru } & & \\
\hline & $\mathrm{F}$ & $\%$ & $\mathrm{~F}$ & $\%$ & $\mathrm{f}$ & $\%$ & $\mathrm{f}$ & $\%$ & $\mathrm{f}$ & $\%$ \\
\hline Pra Sejahtera & 5 & 22.7 & 16 & 72.7 & 1 & 4.5 & 0 & 0 & 22 & 100 \\
\hline KS I & 0 & 0 & 20 & 62.5 & 10 & 31.3 & 2 & 6.3 & 32 & 100 \\
\hline KS II & 0 & 0 & 4 & 23.5 & 11 & 64.7 & 2 & 11.8 & 17 & 100 \\
\hline KS III & 0 & 0 & 0 & 0 & 8 & 61.5 & 5 & 38.5 & 13 & 100 \\
\hline KS III Plus & 0 & 0 & 0 & 0 & 1 & 25.0 & 3 & 75.0 & 4 & 100 \\
\hline Total & 5 & 5.7 & 40 & 45.5 & 31 & 35.2 & 12 & 13.6 & 88 & 100 \\
\hline
\end{tabular}

Dari hasil tabulasi silang tabel 7 menunjukkan bahwa dari 22 responden, 16 responden diantaranya termasuk status ekonomi Pra Sejahtera dan PHBS kategori kuning. Dari hasil tabulasi silang diatas menunjukkan bahwa dari 32 responden, 20 responden diantaranya termasuk status ekonomi Keluarga Sejahtera I dan PHBS kategori kuning. Dari hasil tabulasi silang diatas menunjukkan bahwa dari 17 responden, 11 responden diantaranya termasuk status ekonomi Keluarga Sejahtera II dan PHBS kategori hijau. Dari 13 responden, 8 responden diantaranya termasuk status ekonomi Keluarga Sejahtera III dan PHBS kategori hijau. Dari 4 responden, 3 diantaranya termasuk status ekonomi Keluarga Sejahtera III Plus dan PHBS kategori biru. 


\section{PEMBAHASAN}

\section{Status Ekonomi}

Berdasarkan tabel 5 diatas menunjukkan bahwa sebagian besar status ekonomi responden termasuk Keluarga Sejahtera I yaitu sebanyak 32 orang $(36.4 \%)$. Keluarga Sejahtera I adalah keluarga-keluarga yang telah dapat memenuhi kebutuhan dasarnya secara minimal tetapi belum dapat memenuhi kebutuhan sosial psikologisnya. Kebutuhan dasar secara minimal yaitu kebutuhan pengajaran agama, pangan, sandang, papan dan kesehatan (Setiadi, 2008).

\section{Sebagian} ekonomi dipengaruhi oleh sebagian besar responden berpendidikan SD yaitu sebanyak 40 orang $(45.5 \%)$. Teori Human Capital menerangkan bahwa pendidikan memiliki pengaruh terhadap pertumbuhan ekonomi karena pendidikan berperan di dalam meningkatkan produktivitas kerja. Semakin tinggi mutu pendidikan, semakin tinggi produktivitas kerja, Semakin tinggi pula pertumbuhan ekonomi suatu masyarakat.

Status ekonomi juga dipengaruhi oleh sebagian besar responden bekerja sebagai swasta yaitu sebanyak 38 orang (43.2\%). Pekerjaan biasanya sebagai simbol status sosial ekonomi di masyarakat. Status pekerjaan seseorang yang tinggi akan mempengaruhi pendapatan yang diperoleh oleh seseorang.

\section{Perilaku Hidup Bersih Dan Sehat}

Berdasarkan tabel 6 diatas menunjukkan bahwa sebagian perilaku hidup bersih dan sehat yang dimiliki responden adalah Kuning yaitu sebanyak 40 orang (45.5\%). Karena faktor perilaku hidup bersih dan sehat dipengaruhi oleh umur. Dilihat dari sebagian besar responden berumur 46-55 tahun yaitu sebanyak 71 orang $(80.7 \%)$.

Umur adalah lama hidup individu terhitung saat mulai dilahirkan sampai berulang tahun. Semakin cukup umur, tingkat kematangan seseorang akan lebih matang dalam berfikir dan bekerja, dari segi kepercayaan masyarakat seseorang yang lebih dewasa akan lebih dipercaya dari pada orang yang belum cukup tinggi kedewasaannya.

Umur yang produktif menyebabkan responden cukup matang dalam memilih dan menyaring informasi yang diterima karena bertambahnya umur seseorang akan mempengaruhi kemampuan intelektual dalam menerima informasi sehubungan dengan perilaku hidup bersih dan sehat. Dengan banyaknya infromasi yang diperoleh tentang perilaku hidup bersih dan sehat maka dalam diri responden akan timbul keinginan untuk melaksanakan perilaku hidup bersih dan sehat.

\section{Hubungan Status Ekonomi Dengan Perilaku Hidup Bersih Dan Sehat}

Hasil tabulasi silang tabel 7 menunjukkan bahwa dari 32 responden, 20 responden diantaranya termasuk status ekonomi Keluarga Sejahtera I dan PHBS kategori kuning.

Faktor sosial ekonomi merupakan faktor sangat erat berkaitan dengan penerapan PHBS. Semakin tinggi status sosial ekonomi keluarga antara lain pendidikan, pekerjaan dan kondisi ekonomi 
secara keseluruhan maka semakin baik pula perilaku hidup bersih dan sehat (Furwanto, 2013). Menurut pusat promosi kesehatan, PHBS dapat dapat mencegah terjadinya penyakit dan melindungi diri dari ancaman penyakit. Dampak Perilaku Hidup Bersih dan Sehat (PHBS) yang tidak baik dapat menimbulkan suatu penyakit diantaranya adalah mencret, muntaber, desentri, typus, dan DBD (Syafrizal, 2008).

Oleh karena itu, status ekonomi keluarga yang cukup mampu melaksanakan perilaku hidup bersih dan sehat dengan memenuhi 10 indikator dari PHBS. Contohnya yaitu keluarga selalu mencuci tangan setelah melakukan aktivitas seharihari dengan air bersih dan menggunakan sabun cuci tangan. Sehingga dengan melakukan cuci tangan dapat mencegah terjadinya penyakit yang disebabkan oleh bakteri diantaranya adalah diare, disentri dan typus. Status ekonomi yang tinggi sangat mempengaruhi perilaku hidup bersih dan sehat.

\section{SIMPULAN}

Hasil analisa melalui uji Rank Spearman dengan SPSS, pada taraf kesalahan $5 \%$ dan nilai $\rho$ sebesar 0,000 , dimana $\rho=0,000<0,05$ maka $\mathrm{H}_{1}$ diterima atau $\mathrm{H}_{0}$ ditolak artinya ada hubungan status ekonomi dengan perilaku hidup bersih dan sehat di Dusun Muteran Desa Wonodadi Kecamatan Kutorejo Kabupaten Mojokerto. Semakin tinggi status sosial ekonomi keluarga antara lain pendidikan, pekerjaan dan kondisi ekonomi secara keseluruhan maka semakin baik pula perilaku hidup bersih dan sehat. Status ekonomi sangat erat berkaitan dengan perilaku hidup bersih dan sehat.

\section{SARAN}

\section{Bagi Perangkat Desa}

Hendaknya memperhatikan kondisi ekonomi masyarakat untuk berinovasi supaya penghasilan meningkat dan agar tercapainya perilaku hidup bersih dan sehat yang baik.

\section{Bagi Masyarakat}

Hendaknya

meningkatkan pekerjaan dengan berkarya dan meningkatkan pengetahuan mengenai perilaku hidup bersih dan sehat, sehingga dapat berperilaku hidup bersih dan sehat.

\section{Bagi Peneliti}

Hasil penelitian ini diharapkan dapat dijadikan data awal bagi peneliti yang selanjutnya untuk meneliti faktor lain yang dapat mempengaruhi perilaku hidup bersih dan sehat. Seperti pengetahuan tentang perilaku hidup bersih dan sehat.

\section{DAFTAR PUSTAKA}

Depkes RI. 2006. Perilaku Hidup Bersih dan Sehat di Rumah Tangga. Bakti Husada

Depkes RI. 2007. Rumah Tangga Sehat Dengan Perilaku Hidup Bersih dan Sehat. Bakti Husada

Dinkes, Makasar. 2006. Perilaku Hidup Bersih dan Sehat Perlu Diterapkan http://www.dinkes.com. diakses tanggal 25 Oktober 2017

Dinkes. 2006. Jatim Мепији Egovernment. http://www.dinkes-jatim.com. 
diakses tanggal 25 Oktober 2017

Dinkes. 2008. Perilaku Hidup Bersih dan Sehat Perlu Diterapkan http://www.dinkes.com. diakses tanggal 25 Oktober 2017

Fitriani. 2011. Promosi Kesehatan. Yogyakarta: Graha Ilmu

Friedmen. 2010. Buku Ajar Keperawatan Keluarga. Jakarta : EGC

Furwanto. 2013. Hubungan Status Ekonomi Dengan Penerapan Perilaku Hidup Bersih dan Sehat Tatanan Rumah Tangga http://www.robby_r2hmi@ya hoo.com akses tanggal 05 November 2017

Hartanto. 2010. Perilaku Hidup Bersih dan Sehat. http://www.online.com diakses tanggal 25 Oktober 2017

Hidayat. 2009. Metodologi Penelitian Kebidanan Teknik Analisa Data. Jakarta : Salemba Medika

Irianti. 2010. Buku Ajar Psikologi Untuk Mahasiswa Kebidanan. Jakarta : EGC

Iwan. 2011. Rumah Tangga Sehat. http://www.nakita.com diakses tanggal 25 Oktober 2017

Kartono. 2009. Perilaku Manusia. Jakarta : Rineka Cipta

Kholid, A. 2014. Dengan Pendekatan Teori Perilaku, Media, dan Aplikasinya untuk Mahasiswa dan Praktisi Kesehatan. Jakarta : Rajawali Pers

Nazir. 2005. Metode Penelitian. Bogor : Ghalia Indonesia
Notoatmodjo, S. 2007. Kesehatan Masyarakat Ilmu dan Seni. Jakarta : Rineka Cipta

Notoatmodjo. 2005. Ilmu Kesehatan Masyarakat. Jakarta : PT Rineka Cipta

Notoatmodjo. 2010. Metodologi Penelitian Kesehatan. Jakarta : PT Rineka Cipta

Notoatmodjo. 2010. Pendidikan dan Perilaku Kesehatan. Jakarta : PT Rineka Cipta

Nursalam. 2008. Konsep Penerapan Metodologi Penelitian Ilmu Keperawatan. Jakarta : Salemba Medika

Pieter. 2010. Pengantar Psikologi dalam Keperawatan. Jakarta : Kencana

Riskesdas. 2010. Riset Kesehatan Dasar. Badan Penelitian dan Pengembangan Kesehatan Kementrian RI Tahun 2010

Setiadi. 2008. Konsep dan Proses Keperawatan Keluarga. Yogyakarta : Graha Ilmu

Setiadi. 2013. Konsep dan Praktik Penulisan Riset Keperawatan. Yogyakarta : Graha Ilmu.

Soesetyo. 2008. Pengertian Status Ekonomi. http://www.infokesehatan.com diakses tanggal 05 November 2017

Sugiyono. 2008. Statistik Untuk Kesehatan. Bandung : ALFABETA

Sugiyono. 2016. Metode Penelitian Kuantitatif Kualitatif dan $R$ \& $D$. Bandung : CV Alfabeta.

Suprajitni. 2008. Tingkatan Ekonomi. http://www.blogspot.suprajitn i.com diakses tanggal 05 November 2017

Suprajitno. 2008. Keperawatan Keluarga. Jakarta : PT Rineka Cipta 
Susenas. 2008. Pemantauan Status Ekonomi. Jakarta : EGC

Susilo. 2011. Pendidikan Kesehatan Dalam Keperawatan. Yogyakarta : Nuha Medika

Syafrizal. 2008. Promosi Kesehatan. http://www. Infokesehatan.com akses tanggal 05 November 2017

Yamin, dkk. 2011. Regresi Dalam Genggaman. Jakarta : Salemba Medika

Wawan dan Dewi. 2010. Ilmu Pengetahuan Sikap dan Perilaku. Yogyakarta : Nuha Medika 